\title{
Pemanfaatan E-Learning Sebagai Media Pembelajaran Pada Mata Kuliah Balaghah At-Tathbiqiyyah di STAI Masjid Syuhada Yogyakarta
}

\author{
Ikhwan Nur Rois \\ STAI Masjid Syuhada Yogyakarta \\ roisnur04@gmail.com
}

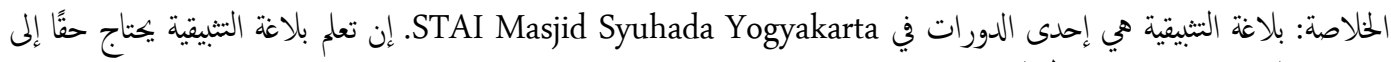

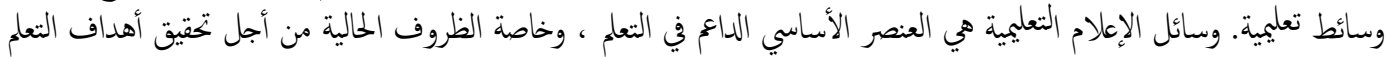

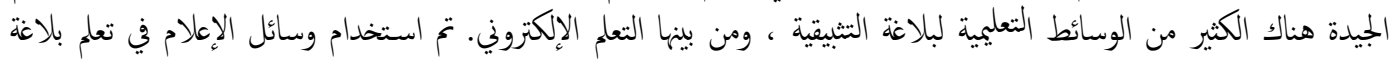

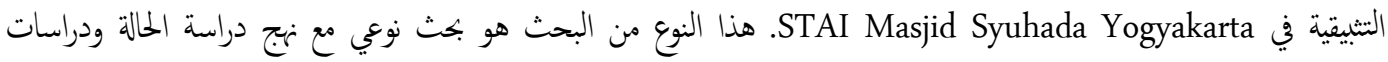

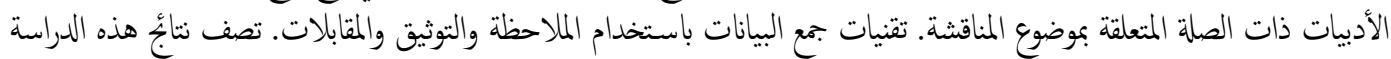

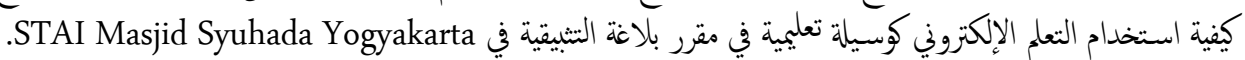

$$
\text { الكلمات المفتاحية: التعلم الإلكتروني ، الوسائط التعليمة ، بلاغة التثيبية. }
$$

\begin{abstract}
Balaghah at-tathbiqiyyah is one of the courses at STAI Masjid Syuhada Yogyakarta. Learning Balaghah at-athbiqiyyah needs a learning media. Learning media is the main supporting element in learning, especially the current conditions to achieve good learning objectives. There are so many learning media for Balaghah at-tathbiqiyyah, one of which is Elearning. The media has been used in learning Balaghah at-tathbiqiyyah at STAI Masjid Syuhada Yogyakarta. This type of research is qualitative research with a case study approach and relevant literature studies related to discussion-data collection techniques using observation, documentation and interviews. The results of this study describe how the use of E-learning as a learning medium in the Balaghah at-tathbiqiyyah course at STAI Masjid Syuhada Yogyakarta.
\end{abstract}

Keywords: E-learning, Learning Media, Balaghah at-Tathbiqiyyah.

\section{PENDAHULUAN}

Bahasa Arab merupakan akar dari segala ilmu pengetahuan baik ilmu agama maupun ilmu dunia, sebagaimana yang penulis dapatkan peta konsep di gedung Pascasarjana UIN Maulana Malik Ibrahim Malang. Hal tersebut dapat dibuktikan bahwa segala ilmu pengetahuan tersebut terdapat pada sumber-sumber agama Islam seperti AlQur'an dan As-Sunnah, selain itu juga dapat kita dijumpai bahwa ilmu-ilmu pengetahuan tersebut dikuasai oleh umat Islam dari zaman sahabat hingga zaman Bani Abbasiyyah, yang mana itu semua tentunya tertulis dengan bahasa Arab.

Bahasa Arab memiliki banyak cabang disiplin ilmu, diantaranya: ilmu nahwu, ilmu shorof, ilmu balaghah, adab, yang mana cabang ilmu bahasa Arab tersebut dipelajari di perguruan tinggi negeri maupun swasta. Pada proses pembelajarannya sangat bersifat 
dinamis, hal ini dibuktikan dengan begitu banyak penemuan baru dalam proses pembelajarannya yang diterapkan oleh para dosen di jenjang perguruan tinggi, baik dari segi pendekatan hingga model pembelajaran serta tak menutut kemudian juga yaitu segi media pembelajarannya, semakin bertambahnya zaman maka semua akan mengikuti sehingga muncul penemuan yang baru ataupun terinovasi guna mempermudah mengajari bahasa Arab.

Pembelajaran bahasa Arab berkaitan dengan lima rukun pembelajaran, diantaranya: pendekatan pembelajaran, metode pembelajaran, tehnik pembelajaran, model pembelajaran dan media pembelajaran. Kelima rukun tersebut bersifat saling menguatkan dan melengkapi dalam proses pembelajaran.

Bahasa Arab di Indonesia telah dipelajari dari tingkat sekolah dasar atau madrasah ibtidaiyyah hingga sekolah menengah atas atau madrasah aliyah dan perguruan tinggi baik negeri dan swasta. Pembelajaran pada jenjang perguruan tinggi dikenal dengan sebutan dosen (guru) dan mahasiswa (siswa) yang mana pada jenjang ini sangat diperlukan sumber daya manusia yang berkualitas agar kelak setelah lulus dapat mengajarkan ilmu secara keseluruhannya dengan baik, terkhusus mata pelajaran bahasa Arab. Pada tulisan ini membahas cabang disiplin bahasa Arab yaitu Balaghah attathbiqiyyah, yang mana ilmu tersebut dipelajari di perguruan tinggi swasta.

Era new normal saat ini menuntut setiap elemen pendidikan menerapkan pembelajarannya secara daring (online), salah satunya STAI Masjid Syuhada. Perguruan ini di bawah Kementerian Agama Republik Indonesia dan di bawah koordinasi KOPERTAIS III Yogyakarta. Peneliti mengamati sejak awal perkuliahan semester gasal ini telah menerapkan pembelajaran melalui daring, oleh karena itu media pembelajaran sangat menjadi garda terdepan pada dunia pendidikan saat ini. Hal ini dibuktikan bahwa pembelajaran Balaghah at-tathbiqiyyah tersebut menggunakan sebuah teknologi yaitu $E$ learning.

E-learning merupakan suatu teknologi berbentuk fitur website yang dimanfaatkan sebagai salah satu media pembelajaran. E-learning dapat digunakan baik melalui smartphone maupun sistem desktop, selain itu E-learning dapat menerima segala format file baik Microsoft word, Microsoft excel, Power point, dan lain sebagainya maupun berupa teks, video, audio. E-learning ini telah digunakan oleh dosen-dosen bahasa Arab sebagai media pembelajaran bahasa Arab di STAI Masjid Syuhada Yogyakarta.

Berdasarkan latar belakang yang telah penulis sampaikan di atas, maka rumusan masalah dalam penelitian ini adalah bagaimana pemanfaatan E-learning sebagai media pembelajaran pada mata kuliah Balaghah at-tathbiqiyyah di STAI Masjid Syuhada Yogyakarta. Adapun tujuan dari penelitian ini adalah untuk mendeskripsikan pemanfataan E-learning tersebut dalam proses pembelajaran Balaghah at-tathbiqiyyah. 


\section{METODE PENELITIAN}

Jenis penelitian ini berupa penelitian kualitatif, suatu penelitian yang menganalisis atau mendeskripsikan suatu fenomena atau masalah yang terjadi, baik berupa peristiwa ataupun aktifitas sosial. Peneliti menggunakan pendekatan studi kasus dan kajian pustaka (library research). Sumber data pada penelitian ini merupakan subjek data-data yang valid dan relevan yang ada di lapangan, yang mana peneliti mengambil sampel menggunakan teknik purposive sampling dan snowball sampling ${ }^{1}$, dengan populasi mahasiswa pendidikan bahasa Arab sebanyak 60 mahasiswa dengan sampel mahasiswa semester tujuh yang berjumlah 20 siswa.

Teknik pengumpulan data dengan observasi, dokumentasi serta wawancara, serta data penguatnya atau sekunder dengan mencari sumber-sumber terkini, baik berupa: buku, berita, tulisan, situs atau desktop. Adapun analisis data menggunakan reduksi data, penyajian data, serta penarikan kesimpulan. Setelah itu dilakukan pengecekan keabsahan data yang diperoleh dengan triangulasi, analisis kasus negatif dengan menggunakan bahan referensi.

\section{PEMBAHASAN}

\section{A. Media Pembelajaran Bahasa Arab}

Kata media merupakan bentuk banyak (jama') yang artinya alat perantaraperantara dan bersifat umum. Adapun bentuk mufrad (satu) berasal dari kata medium, kata tersebut diambil dari bahasa Latin yang artinya alat perantara. Media pembelajaran adalah sebuah alat perantara yang digunakan dalam kegiatan proses pembelajaran.

Menurut Afiffah, dkk (2020: 306) media pembelajaran ialah semua hal serta alat yang dapat mentransformasikan pesan yang dipakai dalam pembelajaran, dimana mampu untuk mencapai target yang diinginkan dalam pembelajaran, meningkatkan semangat para siswa sehingga dalam proses belajar mengajar tercipta suasana yang kondusif dan efisien. Khalilullah (2012) mejelaskan media pembelajaran adalah segala sesuatu yang dapat dilihat dan berfungsi sebagai alat perantara dalam proses pembelajaran dengan tujuan dapat merangsang pikiran, perasaan, dan kemauan siswa. ${ }^{2}$ Sudjana dan Rivai (1991) berpendapat bahwa media pembelajaran berperan sebagai alat bantu guna menciptakan proses pembelajaran secara efektif, yang mana alat bantu tersebut dapat mudah

\footnotetext{
1 Sugiyono. Metode Penelitian Kuantitatif, Kualitatif, dan R\&D. (Bandung: Alfabeta, 2018), 300.

${ }^{2}$ Khalilullah, M. Media Pembelajaran Bahasa Arab. (Yogyakarta: Aswaja Pressindo, 2012), 24.
} 
memahami materi kepada siswa, alat bantu juga bersifat audio visual yaitu dapat dilihat dan didengar. ${ }^{3}$

Media pembelajaran dalam bahasa Arab memiliki beberapa istilah diantaranya al-Wasa'il al-Idhah, al-Wasa'il al-Ta'liim, al-Wasa'il al-Ta'limiyah atau al-Mu'ayyanaat al-Sam'iyah wa al-Bashariyah. Pembelajaran bahasa Arab memiliki fokus empat keterampilan bahasa (al-Maharoh al-Lughoh) yaitu maharah istima', maharah kalam, maharah qiro'ah dan maharah kitabah. Sehingga media pembelajaran bahasa Arab dapat kami definisikan sebagai alat bantu yang digunakan dalam proses pembelajaran bahasa Arab guna memudahkan dalam memahami materi keempat keterampilan bahasa tersebut. ${ }^{4}$

Media pembelajaran saat ini menjadi wajah pembelajaran baik dari sekolah dasar hingga perguruan tinggi yang mana dapat dibuktikan dengan anjuran dari pemerintah terkait kebijakan belajar-mengajar yang dilakukan di rumah masingmasing dan meningkatnya penggunaan media pembelajaran, baik berbasis aplikasi smartphone maupun desktop. Menurut Seels dan Glasgow dalam Arsyad $(2011)^{5}$ membagi media pembelajaran menjadi dua kelompok, yaitu: tradisional dan mutakhir. Media pembelajaran tradisional berupa 1) Visual diam yang diproyeksikan seperti: filmstrips, slides, apaque dan overhead, 2) Visual diam seperti: gambar, poster, foto, grafik, diagram, dan lainnya, 3) Audio seperti: pita kaset, rekaman piringan, reel dan lainya, 4) Penyajian multimedia seperti: tape, 5) Visual dinamis seperti: film, televisi, video, 6) Media cetak seperti: buku, majalah ilmiah, workbook, dan lainnya, 7) Permainan seperti: teka-teki, stimulasi dan permainan papan dan 8) Media realita seperti: model, specimen dan peta boneka. Adapun media pembelajaran mutakhir berupa 1) Media berbasis telekomunikasi seperti: teleconference, kuliah atau belajar jarak jauh, 2) Media berbasis mikroprosesor seperti: computer-assisted instruction, permainan komputer, sistem tutor intelijen.

Media pembelajaran bahasa Arab yang ingin digunakan hendaknya memperhatikan standar pemilihannya, diantaranya: menyesuaikan jenis media dengan materi pelajaran, dapat terjangkau, ketersediaan perangkat keras untuk pemanfaatan media pembelajaran, ketersediaan media pembelajaran di pasaran dan kemudahan dalam memanfaatkannya. Oleh karena itu media pembelajaran bahasa Arab yang digunakan untuk mata kuliah Balaghah at-tathbiqiyyah di STAI

\footnotetext{
3 Sudjana, Nana dan Rivai, Ahmad. Media Pengajaran. (Bandung: Sinar Baru, 1991), 99.

${ }^{4}$ Khalilullah, M. Media Pembelajaran Bahasa Arab. (Yogyakarta: Aswaja Pressindo, 2012), 23.

${ }^{5}$ Arsyad, Azhar. Media Pembelajaran. (Jakarta: Raja Grafindo Persada, 2011), 33
} 
Masjid Syuhada Yogyakarta sudah menyesuaikan dengan standar pemilihan tersebut dan juga situasi serta kondisi proses pembelajaran.

\section{B. Balaghah at-Tathbiqiyyah}

Balaghah at-tathbiqiyyah merupakan salah satu mata kuliah wajib setiap mahasiswa prodi pendidikan bahasa Arab (PBA) yang mana diajarkan pada setiap semester tujuh, dalam pembagian materi kuliah balaghah at-tathbiqiyyah berpedoman dengan kurikulum Kerangka Kualifikasi Nasional Indonesia (KKNI). Balaghah at-tathbiqiyyah diampu oleh bapak Muhamad Fathoni, M.Pd.I yang mana dibagi menjadi empatbelas pertemuan dengan bobot 2 sks.

Materi balaghah at-tathbiqiyyah yang diajarkan di STAI Masjid Syuhada Yogyakarta meliputi tigabelas materi, diantaranya: 1) Ilmu balaghah, 2) Ilmu Bayan (tasybih), 3) Ilmu bayan (hakikat dan majaz), 4) Ilmu bayan (kinayah), 5) Ilmu ma'ani (khabar), 6) Ilmu ma'ani (insya I), 7) Ilmu ma'ani (insya II), 8) Ilmu ma'ani (qashr), 9) Ilmu ma'ani (fashal dan washal), 10) Ilmu ma'ani (musawah, ijaz dan ithnab), 11) Ilmu badi' (keindahan dalam lafadz), 12) Ilmu badi' (keindahan dalam maknawi I), 13) Ilmu badi' (keindahan dalam maknawi II).

Adapun tujuan balaghah at-tathbiqiyyah, diantaranya: 1) Membekali para mahasiswa dengan pengetahuan, keterampilan dan sikap apresiatif terhadap berbagai bentuk gaya bahasa Arab (uslub lughoh) yang dapat digunakan untuk mengapresiasi keindahan bahasa Arab6, 2) Sebagai instrumen utama dalam memahami ilmu adab.

\section{E-learning}

E-learning berasal dari kata electronic learning merupakan suatu proses pembelajaran jarak jauh yang berbasis elektronik. Sistem pembelajaran ini dengan memanfaatkan kecanggihan alat teknologi (perangkat elektronik) yang berkembang saat ini. Michael dalam Sanaky (2009:203) menjelaskan bahwa perangkat eletronik yang dimaksud dalam hal ini adalah perangkat elektronik yang ada kaitannya dengan teknologi informasi dan komunikasi serta multimedia berupa CD, video Tape, TV dan Radio. E-learning adalah proses pembelajaran yang difasilitasi dan didukung melalui pemamfaatan teknologi informasi dan internet.

Selain itu menurut Dong dalam Kamarga mendefinisikan E-learning sebagai kegiatan belajar synchronously (pada waktu yang sama) ataupun asynchronous

6 Yayan, Nurbayan, Pengembangan Bahan Ajar Balaghah Berbasis Pendekatan Adabi. Jurnal Karsa, 22(2), 2014, 138-148. 
(pada waktu yang berbeda) dengan menggunakan perangkat elektronik komputer yang memperoleh bahan belajar yang sesuai dengan kebutuhannya (Sri Rahayu, 2010: 173).

Berdasarkan teori-teori di atas, maka penulis dapat mendefinisikan bahwa E-learning adalah proses pembelajaran jarak jauh berbasis teknologi informasi yang memerlukan suatu jaringan internet untuk mengaksesnya.

E-learning mempunyai karakteristik, diantaranya: (1) Memiliki konten yang relevan dengan tujuan pembelajaran, (2) Menggunakan metode instruksional, misalnya penyajian contoh dan latihan, (3) Membangun pemahaman dan kemampuan yang terkait dengan tujuan pembelajaran baik secara perorangan atau kelompok, (4) Menggunakan elemen-elemen seperti kata-kata dan gambargambar untuk menyampaikan materi pembelajaran (Sanaky, 2009: 208).

E-learning memiliki manfaat, diantaranya: 1) Fleksibel dalam memilih waktu dan tempat untuk mengakses pembelajaran, 2) Lebih mudah diserap, artinya menggunakan fasilitas multimedia berupa gambar, teks, animasi, suara, video, 3) Meningkatkan partisipasi aktif dari mahasiswa karena bisa diakses dimana saja dan bisa kapan saja, 4) Meningkatkan kemampuan belajar mandiri mahasiswa, 5) Meningkatkan kualitas materi pendidik, 6) Meningkatkan kemampuan menampilkan informasi dengan perangkat teknologi informasi.

Kelebihan menggunakan E-learning, diantaranya: 1) Tersedianya fasilitas emoderating di mana dosen dan mahasiswa dapat berkomunikasi secara mudah tanpa dibatasi oleh jarak, tempat dan waktu, 2) Dosen dan mahasiswa dapat menggunakan bahan ajar atau petunjuk belajar yang terstruktur dan terjadwal melalui internet, sehingga keduanya bisa saling menilai sampai seberapa jauh bahan ajar yang dipelajar, 3) Mahasiswa dapat belajar tekait materi perkuliahan setiap saat dan dimana saja kalau diperlukan mengingat bahan ajar akan tersimpan dalam komputer atau handphone, 4) mahasiswa dapat menambah informasi yang berkaitan dengan bahan yang dpelajarinya dengan melakukan akses internet secara lebih mudah, 5) Dosen maupun mahasiswa dapat melakukan diskusi melalui internet yang dapat diikuti dengan jumlah peserta yang banyak, sehinga menambah ilmu pengetahuan dan wawasan yang lebih luas, 6) Berubahnya peran mahasiswa dari biasanya pasif menjadi aktif, 7) Relatif lebih efesien, misalnya bagi mereka yang tidak jauh dari perguruan tinggi atau sekolah konvensional. Sedangkan kekurangan E-learning, diantaranya: 1) Kurangnya interaksi antara dosen dan mahasiswa, kurangnya interaksi ini bisa memperlambat terbentuknya values dalam proses pembelajaran, 2) Kecendrungan mengabaikan aspek akademik atau aspek sosial dan sebaliknya 
mendorong adanya aspek bisnis, 3) Proses pembelajaran cendrung ke arah pelatihan daripada pendidikan, 4) Berubahnya peran dosen dari yang tadinya menguasai teknik konvensional, kini dituntut juga mengetahui teknik pembelajaran yang menggunakan ICT, 5) Mahasiswa yang tidak mempunyai motivasi belajar yang tinggi cendrung gagal, (Sri Rahayu, 2010:176)

\section{Penerapan Media Pembelajaran Balaghah At-Tathbiqiyah melalui $E$ - learning}

Setelah mengetahui makna dan hakikat media pembelajaran beserta pembelajaran berbasis elektronik (E-learning), maka berikut bentuk dan pelaksanaan terhadap penerapan media pembelajaran yang digunakan dosen dalam mata kuliah balaghah at-tathbiqiyah. Pada penerapan ini, peneliti akan membagi menjadi tiga langkah, yaitu: Pertama: tahap persiapan, kedua: tahap pelaksanaan, ketiga: tahap penutupan.

\section{1) Tahap Persiapan}

Tahap persiapan ini, mahasiswa hendaknya mengakses E-learning. Berikut langkah-langkah dalam mengakses E-learning yang disediakan oleh pihak STAI Masjid Syuhada Yogyakarta:

a. Membuka website kampus

Mahasiswa mengakses melalui tautan berikut: https://staimsyk.ac.id/

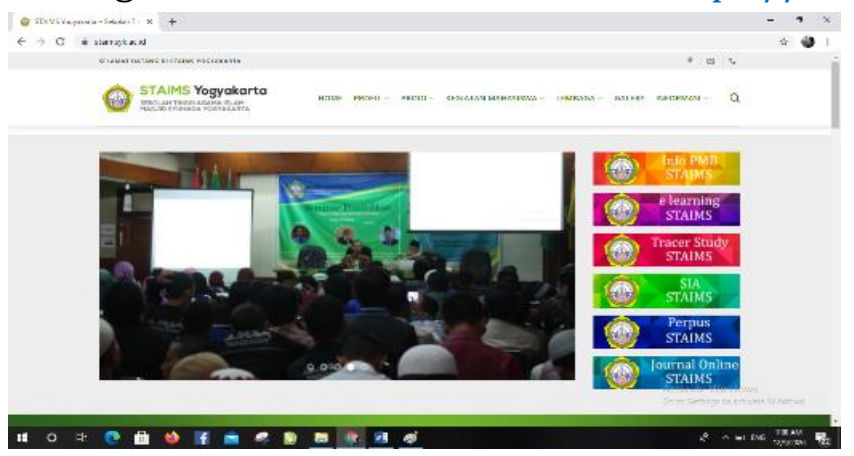

Gambar 1. Website kampus

b. Klik bagian E-learning kampus

Selanjutnya mahasiswa klik E-learning melalui tautan berikut: https://elearning.staims.ac.id/ 


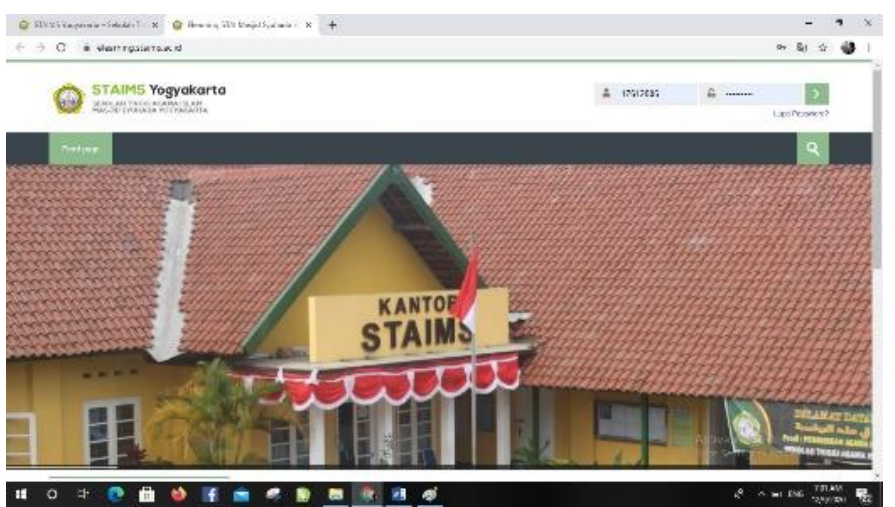

Gambar 2. E-learning kampus

c. Masukkan akun E-learning kampus

Tahap persiapan akhir ialah mahasiswa login ke akun E-learning dengan memasukkan username dan password.

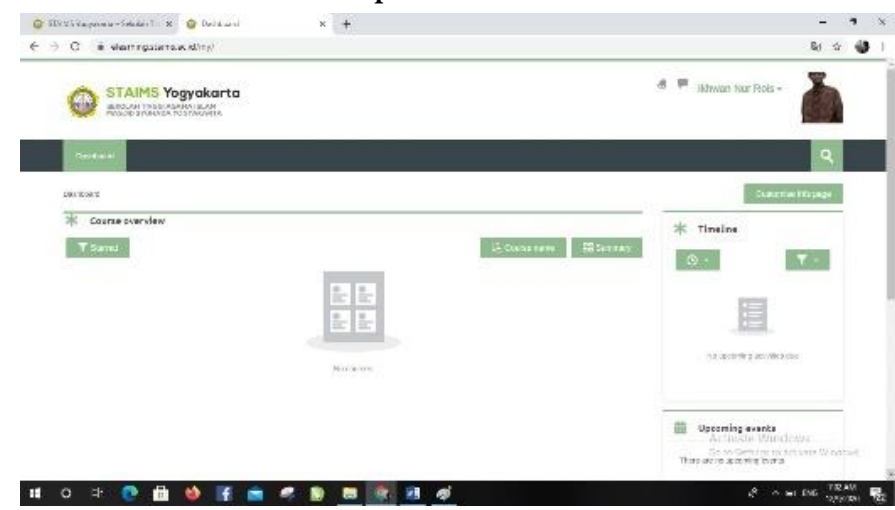

Gambar 3. Akun E-learning kampus

\section{Tahap Pelaksanaan}

Tahap pelaksanaan ini, mahasiswa sudah siap untuk mengikuti pembelajaran yang akan disampaikan oleh dosen. Berikut langkah-langkah yang dapat dilakukan tahap pelaksanaan:

a. Masuk ke dashboard mata kuliah

Mahasiswa dapat melihat pada dashboard mata kuliah balaghah attathbiqiyyah seperti berikut: 


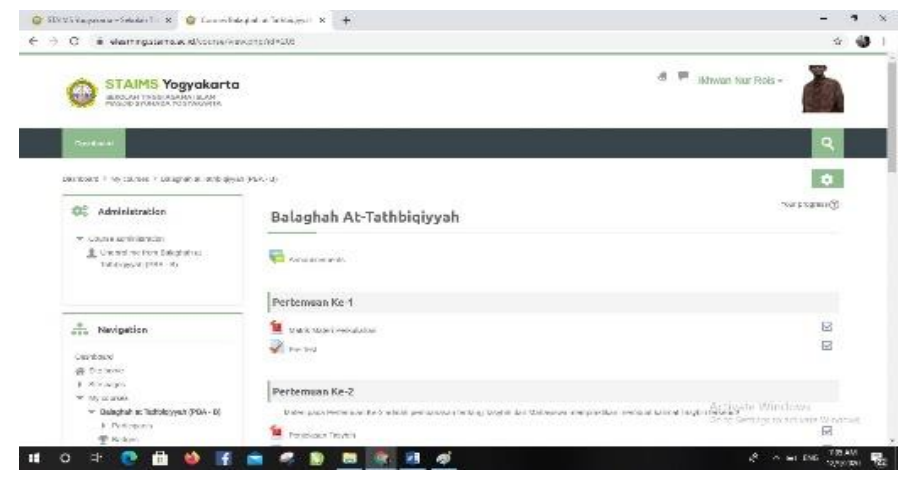

Gambar 4. Dashboard mata kuliah

b. Membuka materi mata kuliah

Materi yang diberikan berupa file pdf, yang mana materi-materi yang disampaikan dapat di unduh dan di simpan pada perangkat desktop ataupun handphone. Berikut contoh materi pada pertemuan kedua mata kuliah balaghah at-tathbiqiyyah:

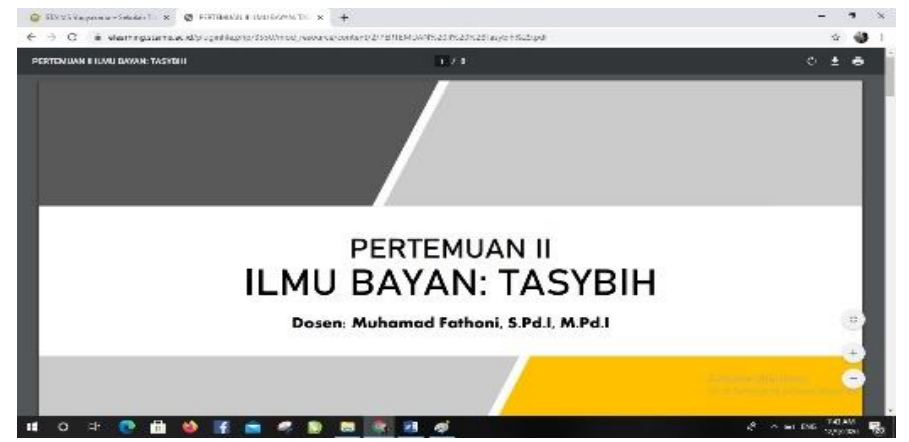

Gambar 5. Materi mata kuliah

c. Mengikuti ruang diskusi

Mahasiswa dalam pembelajarannya juga dapat melakukan diskusi pada ruang diskusi yang tersedia, ruang diskusi ini ada dua bagian yaitu: ruang diskusi umum dan ruang diskusi ruang khusus.

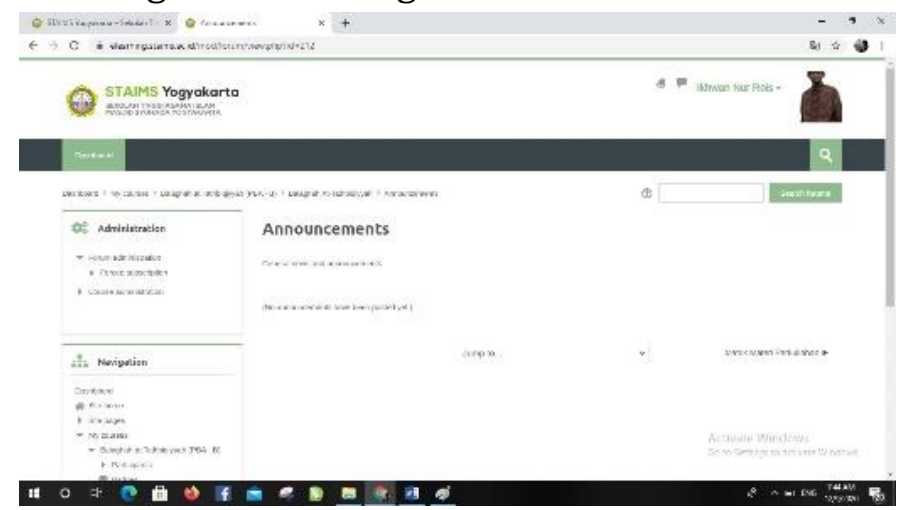

Gambar 6. Ruang diskusi umum 


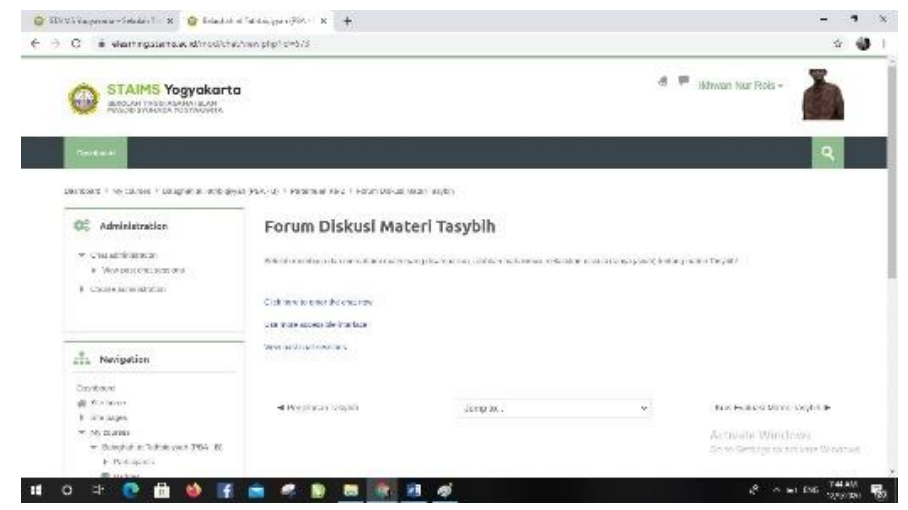

Gambar 7. Ruang diskusi khusus

\section{Tahap Penutupan}

Tahap penutupan ini, dosen melalukan evaluasi pembelajaran dalam bentuk kuis atau google form. Hal ini bertujuan untuk mengetahui tingkat pemahaman materi yang telah diajarkan pada setiap pertemuan, yang mana bentuk evaluasi ini berupa tugas mandiri yang dikerjakan melalui layanan google form atau kuis dengan batas waktu yang ditentukan dosen.

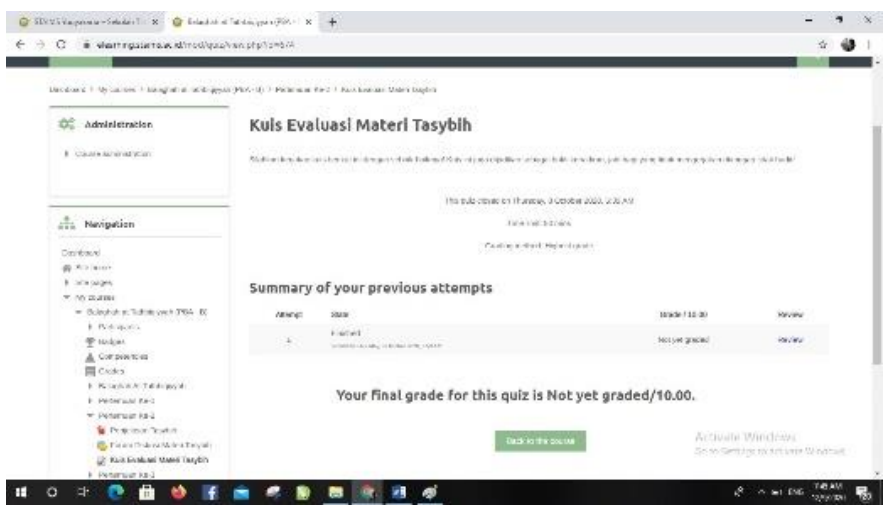

Gambar 8. Evaluasi berupa kuis

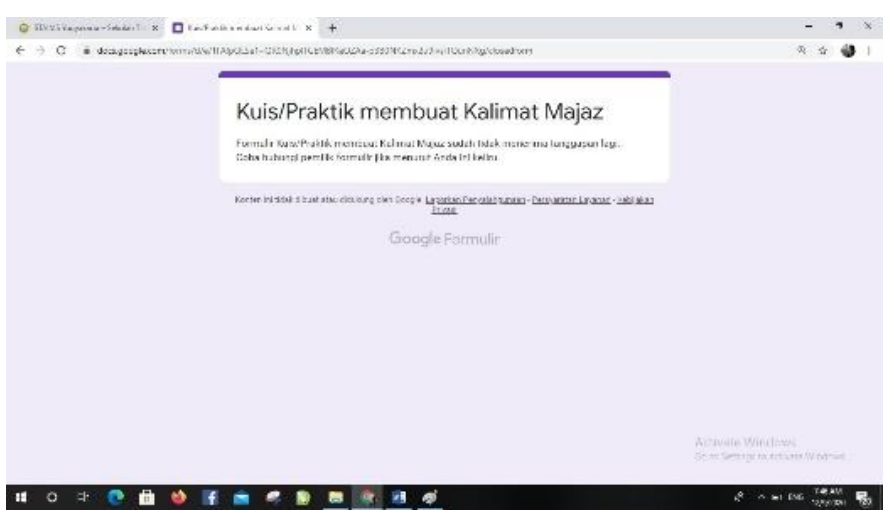

Gambar 9. Evaluasi berupa Google Form

Ihtimam: Jurnal Pendidikan Bahasa Arab- Volume 04, Nomor 01, Juni 2021 
Pemanfaatan E-learning ini tidak hanya dilakukan pada mata kuliah balaghah at-tathbiqiyyah, akan tetapi juga diterapkan pada semua mata kuliah yang dipelajari pada semester tujuh, diantaranya: I'dad al-ikhtibaraat ALBA, Preparation for EIFEL dan lainnya. Adapun cara untuk memanfaatkan E-learning pada setiap mata kuliah akan berbeda, hal ini menyesuaikan materi-materi yang akan dipelajari.

\section{KESIMPULAN}

Berdasarkan pembahasan di atas, maka dapat disimpulkan bahwa pemanfaatan $E$ learning sebagai media pembelajaran balaghah at-tathbiqiyyah di STAI Masjid Syuhada Yogyakarta sudah sangat sesuai dengan kondisi saat ini, di lain sisi juga harus bisa lebih memanfaatan media pembelajaran E-learning secara maksimal. Media pembelajaran dalam pemilihannya juga dapat menyesuaikan dengan materi yang akan disampaikan agar para mahasiswa mudah memahami dan asyik mengikuti pembelajaran, terkhusus mata kuliah balaghah at-tathbiqiyyah. Selanjutnya diharapkan tulisan ini dapat menjadi referensi atau rujukan tulisan untuk penelitian selanjutnya yang terkait topik pembahasan yang relevan.

\section{DAFTAR PUSTAKA}

Arsyad, Azhar. 2011. Media Pembelajaran. Jakarta: Raja Grafindo Persada.

Chandrawati, Sri Rahayu. 2010. Pemanfaatan E-Learning Dalam Pembelajaran. Jurnal Cakrawala Kependidikan, 8(2), 171-181.

E-Learning STAI Masjid Syuhada Yogyakarta. https://elearning.staims.ac.id/

Khalilullah, M. 2012. Media Pembelajaran Bahasa Arab. Yogyakarta: Aswaja Pressindo.

Nurbayan, Yayan. 2014. Pengembangan Bahan Ajar Balaghah Berbasis Pendekatan Adabi. Jurnal Karsa, 22(2), 138-148.

Prananingrum, Afiffah Vinda dkk. 2020. Kajian Teoritis: Media Pembelajaran Bahasa Arab. Prosiding Konferensi Nasional Bahasa Arab Universitas Malang, No. 6(2020).

Sanaky, Hujair AH. 2009. Media Pembelajaran. Yogyakarta: Safiria Insania Press.

Sudjana, Nana dan Rivai, Ahmad. 1991. Media Pengajaran. Bandung: Sinar Baru.

Sugiyono. 2018. Metode Penelitian Pendidikan: Pendekatan Kuantitatif, Kualitatif, dan $R \& D$. Bandung: Alfabeta. 